\title{
O ESPAÇO-TEMPO DA GRAMATIZAÇÃO BRASILEIRA: UMA AGENDA DIALETOLÓGICA NA LINGUÍSTICA NACIONAL
}

\author{
THE SPACE-TIME OF BRAZILIAN GRAMMATIZATION: A \\ DIALECTOLOGICAL AGENDA IN NATIONAL LINGUISTICS
}

\author{
Marcelo Rocha Barros Gonçalves ${ }^{1}$ \\ Universidade Federal de Mato Grosso do Sul (UFMS)
}

\begin{abstract}
RESUMO
Este trabalho propõe a discussão da temática da espacialidade na Linguística brasileira e seu funcionamento na relação língua/sujeito/estado num período que vai do final do século XIX a meados do século XX. Trabalhamos dentro de uma perspectiva discursiva, como diz Orlandi (2001), utilizando as considerações de Auroux (2009) sobre o processo de gramatização e sobre os instrumentos tecnológicos deste processo, como os dicionários e as gramáticas. Tentamos investigar como estas tecnologias linguísticas produzem discursos num determinado espaço-tempo brasileiro, e como estes discursos se relacionam para a constituição da língua portuguesa. Dentro de uma política de línguas do final do século XIX, é a partir deste discurso sobre a espacialidade brasileira que poderemos pensar numa série de práticas que vão afastar a língua portuguesa falada no Brasil da de Portugal, e, mais tarde, tentar confirmar a unidade de uma língua nacional. Contraditoriamente, é a partir desta mesma unidade imaginária que as questões sobre a diversidade concreta da língua falada em território nacional vão surgir e ganhar força. Em nossa perspectiva, percebemos a construção e o funcionamento de uma agenda de cunho dialetológico que permeará os Estudos da Linguagem no Brasil.
\end{abstract}

PALAVRAS-CHAVE: História das Ideias Linguísticas; Gramatização brasileira; Linguística Nacional; Dialetologia.

\begin{abstract}
This work proposes the discussion of the theme of spatiality in Brazilian Linguistics and its functioning in the language / subject / state relationship in a period that goes from the end of the 19th century to the mid-20th century. We work within a discursive perspective, as Orlandi (2001) says, using Auroux's (2009) considerations on the grammatization process and on the technological instruments of this process, such as dictionaries and grammars. We try to investigate how these linguistic technologies produce discourses in a given Brazilian space-time, and how these discourses are related to the constitution of the Portuguese language. As a language policy of the end of the 19th century, in one hand it is from this discourse on Brazilian spatiality that we can think of a series of practices that will move away the Portuguese language spoken in Brazil from that of Portugal, and, in other, try to confirm the unity of a national language. Contradictorily, it is from this same imaginary unit that questions about the concrete diversity of the language spoken in the national territory will arise and gain strength. In our perspective, we perceive the construction and functioning of a dialectical agenda that will permeate Language Studies in Brazil.
\end{abstract}

KEYWORDS: History of Linguistic Ideas; Brazilian Grammatization; National Linguistics; Dialectology.

\footnotetext{
${ }^{1}$ Doutor em Linguística, professor associado da UFMS e pós-doutorando em Linguística pela UFSCar. Email: marcelo.barros@ufms.br
} 


\section{INTRODUÇÃO}

Este trabalho, na área da História das Ideias Linguísticas, propõe a discussão da temática da espacialidade na Linguística brasileira e seu funcionamento na relação língua/sujeito/estado num período que vai do final do século XIX a meados do século XX. Secundariamente, apresentamos uma proposta de periodização da constituição da língua portuguesa falada no Brasil, para refletir, a partir desta proposta, a permanência de uma agenda dialetológica nos estudos linguísticos. Não tomamos o termo espacialidade exatamente na perspectiva da "decolinialidade" proposta por Mignolo (2003, p. 46) e da "língua como prática local” de Pennycook (2010, p. 135).

De qualquer maneira, Castanheira (2017, p. 83) apresenta uma proposta bastante interessante quando analisa as "implicações políticas do tratamento das espacialidades na linguística”, na relação entre práticas linguísticas e espacialidades. Trabalhamos aqui dentro de uma perspectiva discursiva, ou como diz Orlandi (2001, p. 27), aquela que pensa a língua em sua história e seu funcionamento:

Em termos teóricos não é pequena a contribuição de tal perspectiva quando pensamos que a própria maneira de encarar a constituição da língua nacional, de concebê-la em sua historicidade, produz uma maneira de nos inscrevermos, com nossos métodos, em um domínio específico da história das ciências. [...] Não se está aí, pois, no domínio de uma epistemologia positivista mas histórica, isto é, na qual não há separação e hierarquia entre sujeito-objeto, dado-constructo, interior-exterior, abstrato-concreto, e na qual a história não é evolução e continuidade, mas deslocamento e funcionamento (ORLANDI, 2001, p. 27).

Iniciamos nossa discussão utilizando as considerações de Auroux (2009) sobre o processo de gramatização e sobre os instrumentos tecnológicos deste processo, como os dicionários e as gramáticas. Tentamos investigar como estas tecnologias linguísticas produzem discursos num determinado espaço-tempo, e como estes discursos se relacionam para a constituição de uma dada língua, neste caso o português brasileiro.

Duas sensíveis complementações às pesquisas iniciadas por Auroux (2009) podem ser realizadas em face da própria realidade brasileira: de um lado rever o lugar da constituição de uma língua nacional e seus sujeitos agora em um ambiente de colonização, e de outro lado, agregar à análise as chamadas novas práticas de leitura propostas pela análise de discurso francesa e que trabalham de maneira característica a construção de arquivos, ou seja, a leitura da história, a sua interpretação.

Observamos para a construção do arquivo $^{2}$ deste trabalho, inicialmente balizada pelo processo da gramatização brasileira no fim do século XIX, que havia uma série de textos em que a questão da espacialidade brasileira estava colocada, direta ou indiretamente, e que isso produzia efeitos não só para determinadas disciplinas dos estudos da linguagem, como a lexicografia, a filologia e a dialetologia, mas para a Linguística brasileira de um modo geral, pensada dentro do ambiente teórico de uma História das Ideias Linguísticas no Brasil.

Como então dar conta, num período relativamente longo de tempo, de textos ao mesmo tempo tão díspares e tão próximos?

Os trabalhos de Said (2007 e 2011) sobre a questão do oriente no Orientalismo e no livro Cultura e Imperialismo foram inspiradores para o desenvolvimento desta pesquisa. No primeiro principalmente, Said vai tomar, entre outras, a definição do Oriente como um

\footnotetext{
2 Pensamos aqui como Mazière (2007, pg. 96): “A adoção do "trajeto temático” permite, ao mesmo tempo, aninhar o conteúdo em um tema e analisá-lo linguisticamente, por meio da heterogeneidade dos gêneros, em um corpus aberto. Correlativamente, pode-se desenvolver a noção de "arquivo" como corpus de AD".
} 
discurso, em referência direta à arqueologia de Foucault (2004). Diz Said (2007) no prefácio da edição de 2003:

Minha argumentação é que, sem examinar o Orientalismo como um discurso, não se pode compreender a disciplina extremamente sistemática por meio da qual a cultura europeia foi capaz de manejar - e até produzir - o Oriente política, sociológica, militar, ideológica, científica e imaginativamente durante o período do pós-Iluminismo. Além disso, o Orientalismo tinha uma posição de tal força que ninguém escrevendo, pensando ou agindo sobre o Oriente poderia fazê-lo sem levar em consideração as limitações ao pensamento e à ação impostas por ele (SAID, 2007, p. 29-30).

O primeiro passo foi tomar a questão da temática da espacialidade brasileira também como um discurso, e, como tal, era preciso contextualizá-lo historicamente, contextualizá-lo politicamente. Era preciso entender seu funcionamento dentro da relação língua/sujeito/estado numa situação específica do território nacional e pensá-lo a partir de suas próprias condições de produção ${ }^{3}$.

Dissemos politicamente porque do ponto de vista histórico que estabelecemos, estamos interessados em relacionar a constituição deste discurso sobre a espacialidade brasileira aos projetos de construção da nação brasileira e da língua nacional, fortalecidos no final do século XIX com a proclamação da República. Em última análise, gostaríamos de compreender como se dá o funcionamento deste discurso dentro de uma política de línguas, dentro de uma política linguística brasileira.

Dentro de uma política de línguas, é a partir deste discurso sobre a espacialidade brasileira que poderemos pensar numa série de práticas ${ }^{4}$ que vão afastar a língua portuguesa falada no Brasil da de Portugal, e, mais tarde, tentar confirmar a unidade de uma língua nacional. Contraditoriamente, é a partir desta mesma unidade imaginária que as questões sobre a diversidade concreta da língua falada em território nacional vão surgir e ganhar força e moldar a linguística nacional.

Nosso percurso dar-se-á então, inicialmente, com a discussão sobre o processo de gramatização, sua adequação ao espaço-tempo brasileiro e seus efeitos para o desenvolvimento da Linguística no Brasil.

\section{0 processo da gramatização}

Para a crítica de Auroux (2009), há um sério problema na forma tradicional de se fazer História da Linguística: o de considerar a Linguística como uma forma de saber cuja organização e cujas propriedades formais seriam estáveis. A constituição do saber linguístico é cotidiana, dinâmica e, como todo conhecimento é uma realidade histórica, importa mais compreender as relações deste saber com a sua espessura temporal, seu horizonte de retrospecção e seu horizonte de projeção do que organizá-lo na "atemporalidade ideal da ordem lógica do desfraldamento do verdadeiro" (AUROUX, 2009, p.12).

Auroux (2009) coloca a questão da constituição do saber linguístico em outros termos. No A Revolução Tecnológica da Gramatização, duas teses permitem revisitar a História da Linguística sob outro ponto de vista:

\footnotetext{
3 Ver Pêcheux (1990).

4 Vamos pensar nestas práticas não só a partir da definição foucaultiana de práticas discursivas (Ver Foucault, 2004), mas também como um conjunto de procedimentos que leva à produção de instrumentos linguísticos, como gramáticas e dicionários.
} 
(i) diferentemente do que imaginam frequentemente os historiadores, os linguistas e os filósofos sobre o nascimento das ciências da linguagem, Auroux (2009) coloca a escrita como meio e não produto das ciências da linguagem;

(ii) "o Renascimento europeu é o ponto de inflexão de um processo que conduz a produzir dicionários e gramáticas de todas as línguas do mundo (e não somente dos vernáculos europeus) na base da tradição greco-latina" (AUROUX, 2009, p.8).

O panorama geral apresentado por Auroux (2009) para a constituição das ciências da linguagem está de alguma forma relacionado ao modo de constituição do saber metalinguístico, em sua relação de continuidade com a esfera epilinguística. Os momentos de ruptura desta continuidade (as revoluções) compreendem o advento da escrita em 3.000 a. C. e a gramatização massiva do séc. V d. C. até os fins do século XIX. Assim, a escrita seria a tecnologia da $1^{\mathrm{a}}$ revolução técnico-linguística, ao passo que os dicionários e as gramáticas seriam as tecnologias da $2^{\mathrm{a}}$ revolução técnico-linguística.

Faço minhas as palavras de Auroux (2009, pg.76), quando define o fenômeno da gramatização:

\begin{abstract}
Deve-se fazer começar a gramatização com o aparecimento do primeiro saber metalinguístico de uma língua dada (por exemplo, quando se começam a citar palavras ou expressões em um texto de outra língua). É, no entanto, preciso que esse aparecimento seja a primeira margem significativa de uma série que se prolonga sem muita continuidade até a redação de gramáticas e dicionários [...]. De direito, o processo de gramatização nunca termina, porque, de um lado, as línguas evoluem, e, de outro, é difícil definir até onde se pode levar o processo de gramatização, cuja extensão foi muito variável segundo as línguas. Podemos, todavia, nos entender sobre o que significa para uma língua "ser gramatizada". É quando podemos falá-la (ou lê-la), em outras palavras, aprendê-la (em um sentido suficientemente restrito), com a ajuda apenas dos instrumentos linguísticos disponíveis (AUROUX, 2009, p.76).
\end{abstract}

Por fim, uma pequena nota: os instrumentos linguísticos, além de dicionários e gramáticas, vale dizer, também podem ser redigidos em outros gêneros, na forma de revistas de divulgação científica, de manuais, etc..., ou até mesmo como trabalhos não acadêmicos (aqui especialmente os de cunho descritivista da variedade falada no Brasil), desde que a questão metalinguística esteja posta, ou seja, um saber sobre uma dada língua em contraste com outra apareça numa série, num espaço-tempo específico.

\title{
2 A gramatização brasileira
}

No Brasil, o processo de gramatização tomou formas diferentes, em face da própria realidade linguística nacional. O estudo iniciado por Eni Orlandi em parceria com o Grupo da Paris VII sobre o corpus do Brasil viabilizou, principalmente aos pesquisadores da História das Ideias Linguísticas no Brasil, a retomada do processo de gramatização em função da complexidade em que se mostrava em outro espaço que não o do contexto europeu. Por mais que a língua portuguesa fosse a introduzida no Brasil a partir de 1500 com o início da colonização, aquilo que se aceitou acertadamente chamar de gramatização brasileira representa muito mais a realidade nacional do que uma mera extensão da língua de Portugal em solo colonizado.

A primeira dificuldade posta ao pesquisador é a de acertar o batimento entre o processo de gramatização no contexto europeu e no contexto brasileiro. No Brasil, o contato da língua colonizadora se dá com diferentes línguas - indígenas, africanas, etc.-, e em diferentes momentos. Lembramos com Orlandi (2001) que, diferentemente das nações europeias, a realização de um estado (arriscamos dizer nação) independente de Portugal, no 
Brasil, acontecia séculos depois da língua portuguesa já ter sido introduzida pelos colonizadores portugueses.

Para o processo de gramatização brasileira deve-se levar em conta o trabalho dos jesuítas com os índios, a chegada dos negros para o trabalho no ouro e no café, a utilização da língua geral pelos bandeirantes, etc. Mais do que isso, nesta extensa espessura temporal, serão relevantes também as discussões em torno da língua nacional brasileira quando a relação língua/estado/nação é posta em xeque pela Independência. Ainda que o processo de legitimação do português tenha se iniciado muito antes (pensemos na política linguística de Pombal), a Independência, e mais tarde a Proclamação da República, deslocam a representação da língua nacional enquanto tal: língua de que nação, que língua?

Conceber a língua portuguesa num desdobramento entre o português de Portugal e o do Brasil é permitir analisar não mais a relação de uma língua fonte e de uma língua alvo, mas suas próprias relações internas de regularidade e diversidade que se constituem num espaço-tempo distinto, como hiperlínguas diferentes. Nas palavras de Orlandi (2001, p.13):

[...] Desde o fim do séc. XVI, a língua falada no Brasil já não é a mesma que se fala em Portugal. Da vida e das práticas dos sujeitos que aqui se encontravam se formava progressivamente a sociedade brasileira. Mas a legitimidade dessa sociedade com suas próprias instituições, seu saber, suas práticas linguísticas, seu poder político é elaboração particular do século XIX. Com a Independência, em 1822, o Estado brasileiro se constitui como tal e a questão da Língua Nacional se coloca. Até então, embora já existissem variações concretas, politicamente não se dava visibilidade a essa diferença. Com a independência e a institucionalização da sociedade brasileira a questão da Língua Nacional se apresenta de forma determinada: Língua e Estado devem se conjugar em sua fundação (ORLANDI, 2001, p.13).

Para Orlandi (2001), a segunda metade do séc. XIX é o ponto inicial da gramatização brasileira. $\mathrm{Na}$ visão da autora, a independência política do Brasil recoloca a discussão sobre a relação entre as línguas num novo espaço-tempo. Diferentemente do passado colonial, quando havia predominância de outras línguas, ou quando a língua falada no espaço linguístico brasileiro era remetida para a representação do Estado, é somente a partir do séc. XIX que a língua portuguesa passa a "signo da nacionalidade", conforme Orlandi (2001, p.24).

Há nesse período um intenso trabalho de construção do aparelho institucional que permite tratar o processo de gramatização de outra forma, pensando na formação de brasileiros. As tecnologias científicas e as instituições, que representam para Orlandi (2001) uma nova instrumentação, acarretam em uma maneira diferente de se posicionar em relação à questão da língua falada no Brasil, agora distinta da de Portugal. A mudança na tradição gramatical que se processou durante este período tem ainda no Brasil o particular de promover questões relativas ao ensino do português no Brasil.

No Rio de Janeiro, naquela época capital do país, Fausto Barreto do Colégio Pedro II recebeu a solicitação do Diretor Geral da Instrução Pública, Emídio Vitório, para organizar o Programa de Português para os Exames Preparatórios ${ }^{5}$. Para esta solicitação a resposta brasileira foi de produção de uma série de instrumentos linguísticos voltados a este programa (mais especificamente gramáticas) ${ }^{6}$. O que muitas destas gramáticas faziam além de respeitar as instruções do programa era dizer que rompiam com a tradição portuguesa

\footnotetext{
${ }^{5}$ Os exames funcionavam como critério para admissão nos cursos universitários.

${ }^{6}$ A portaria é de 05 de abril de 1887. Ver Maciel (1928), p. 502.
} 
da gramática filosófica. Orlandi (2001, p. 36) toma como exemplo, entre outras, as gramáticas de Júlio Ribeiro e de João Ribeiro, de 1887 e 1881:

Com efeito, é pela Escola, pelos debates, manuais, publicações em geral que se formulará esta relação da ciência e da língua com a formação da Nação. A política intervirá com a Proclamação da República no Brasil. Especificamente com relação à sua língua, ser autor de gramática é ter uma responsabilidade como homem de ciência e ter uma posição de autoridade em relação à singularidade do português do Brasil (ORLANDI, 2001, p. 36).

Bem mais tarde, já em 1959, a Nomenclatura Gramatical Brasileira (NGB) foi estabelecida por um decreto do Ministério da Educação e da Cultura e tornou obrigatória (oficial) para o ensino no Brasil uma nomenclatura (fixa) dos fatos gramaticais. Consideramos a NGB um fator decisivo no processo de constituição da língua nacional ${ }^{7}$ que põe fim ao processo de gramatização brasileira.

\section{A ideia de agenda}

Tomamos emprestado o termo agenda de Toulmin (1992) para caracterizar melhor este discurso e suas práticas, sua permanência numa História das Ideias Linguísticas sobre a espacialidade brasileira. $\mathrm{Na}$ proposta original, o termo é utilizado para tratar em conjunto das características do pensamento moderno, e lhe permite estabelecer duas correntes distintas da modernidade. Uma corrente cientificista, melhor representada na figura do filósofo francês René Descartes e outra de caráter mais humanístico, movida pelos ideais do Renascimento Europeu, representada por Montesquieu.

Diferentemente de Toulmin (1992), não consideramos esta agenda como algo que está escondido ${ }^{8}$ ou algo que está para ser descoberto. Nossa proposta visa destituir uma mera análise de conteúdo da matéria e pretende tornar possível a análise do arquivo, organizando-o em função do conjunto de procedimentos e instrumentos linguísticos criados para a interpretação da espacialidade no território nacional - por isso uma agenda dialetológica.

Como na arqueologia de Foucault (2005, vol. II, pg. 146), não estávamos interessados em estudar "o começo no sentido da origem primeira" nem "as relações [...] secretas, mais silenciosas ou mais profundas do que a consciência do homem". O que tentamos fazer é "definir relações que estão na própria superfície dos discursos, [...] tornar visível o que só é invisível por estar muito na superfície das coisas".

O discurso é problematizado em relação ao campo dos acontecimentos discursivos e está, portanto, dentro de um domínio determinável na própria superfície de sua manifestação, no próprio acontecimento que o torna discurso manifesto. Não basta, assim, o estudo descritivo destes discursos manifestos, em seus domínios impostos pelos próprios campos enunciativos, campos de saber, mas é também producente entender as relações entre estes discursos e seus campos, suas regras de coexistência.

Foucault (2005) alerta para alguns dos motivos que o levaram a adotar a ideia de que certos enunciados, a partir do estudo de suas relações, poderiam formar um conjunto ora porque se referiam a um determinado objeto, ora pelo tipo de enunciação utilizada, ora pela existência de uma série de conceitos permanentes e coerentes entre si, ora por fim, no

\footnotetext{
${ }^{7}$ Sobre a NGB, ver Baldini (1999).

${ }^{8}$ No original, o subtítulo é The hidden agenda of modernity - grifo nosso (Cf. TOULMIN, 1992).
} 
extremo, pela formação de um conjunto de noções muito dispersas e bastante heterogêneas.

Desta maneira, nos esclarece Foucault (2005, vol. II, p.105) que:

[o] que permite individualizar um discurso é atribuir-lhe uma existência independente, é o sistema de pontos de escolha que ele deixa livre a partir de um campo de objetos dados, a partir de uma gama enunciativa determinada, a partir de uma série de conceitos definidos em seu conteúdo e em seu uso (FOUCAULT, 2005, vol. II, p.105).

Para nós, portanto, a agenda é ao mesmo tempo discurso, mas também um conjunto de práticas, inclusive metodológicas (e porque não epistemológicas) que irá permear os estudos da linguagem no Brasil.

\title{
4 Efeitos da gramatização brasileira
}

Dentro deste contexto da gramatização brasileira, partimos da hipótese de que é possível pensar na constituição de uma agenda linguística para a espacialidade brasileira a partir do último quarto do século XIX. Admitimos, primeiramente, uma série de coincidências entre o processo de gramatização no Renascimento na Europa e no Brasil, seja na conservação e acumulação de um saber empírico elementar, seja na oposição entre uma língua I em relação a uma língua II em gramatização.

Será possível detectar, no caso brasileiro inclusive, exemplos de utilização de uma mesma metodologia de comparação entre as línguas, como no caso de Garcia (1920) ${ }^{9} \mathrm{com}$ a análise de tradução interlinear entre o português, o francês e o tupi, semelhante ao ocorrido com o tâmul, o chinês, o finês para enumerar alguns dos exemplos de Auroux ( 2009, p.82-84).

O espaço linguístico brasileiro ${ }^{10}$ estaria sendo assim redefinido, retomado a partir dos efeitos do processo de gramatização da "língua" brasileira pelo português do "novo" Brasil. Reconhecer, no caso de um país (des)colonizado, que ele tem uma esfera externa e interna em relação à sua própria constituição linguística é por fim reconhecer a si mesmo como entidade linguística. Reconhecia-se a diferença da língua portuguesa falada no Brasil, ainda que, não no mesmo ritmo, se iniciavam as descrições da diversidade da língua falada em território nacional. Como vê Orlandi (2001, p.35):

\begin{abstract}
A gramatização em um país colonizado trabalha segundo um duplo eixo: o da universalização, o dos deslocamentos. Ter uma gramática, nestas condições, significa ter direito à universalidade, ter direito à unidade (imaginária) constitutiva de toda identidade. Por outro lado, falar dos "usos variados" é defender uma "outra" língua. Com efeito, uma vez conquistado o direito à unidade, imediatamente recomeça-se a reconhecer as variedades: a influência da língua dos índios, das línguas africanas, etc. Este reconhecimento é o próprio da constituição da unidade do Português Brasileiro (ORLANDI, 2001, p.35).
\end{abstract}

Há, contudo, um pequeno problema em aceitar sem restrição, como efeito direto da gramatização, o trabalho contrastivo entre as línguas envolvidas. Talvez, a peculiaridade do processo de gramatização no Brasil é que ele tenha se dado por vezes na base de uma mesma língua. Podemos pensar, por exemplo, numa das características (mais ou menos

\footnotetext{
${ }^{9}$ Estamos fazendo referência à publicação do texto Phrases e Discursos tupis de Rodolfo Garcia, no n.5 de 1920 da Revista de Língua Portuguesa dirigida por Laudelino Freire. Ver Freire (1919).

10 Ver a hipótese de Guimarães (2007) sobre o modo de funcionamento das línguas no espaço linguístico (de enunciação) brasileiro: língua materna/alheia/franca x nacional/oficial/estrangeira (Ver ORLANDI, 2007b).
} 
geral) do processo de ter uma gramática: a tradução entre as línguas no Brasil feita como lista de palavras ocorria dentro do próprio português.

No espaço-tempo brasileiro, diferentemente do europeu, o português havia se tornado a língua do estado, primeiro da monarquia (diga-se portuguesa), e depois da república, durante o período da gramatização... Mas um português brasileiro (diverso do de Portugal) que tomava a posição de língua de estado, de língua de nação e de língua de literatura, etc... ainda na segunda metade do século XIX. Assim, para Orlandi (2007a) e Auroux (2009) a gramatização endógena da língua brasileira vai interferir na relação língua/estado/nação.

Vejam que, no Brasil daquele tempo, pensar então na constituição de uma agenda, que toma por objeto/fim construir uma gramática contrastiva é apontar para a diversidade externa e interna da própria língua portuguesa. Constituir, portanto, uma gramática contrastiva da língua portuguesa seria compreender a própria realidade da língua falada no Brasil em relação à língua portuguesa de Portugal.

Apoiada numa nova orientação teórica e filosófica, esta gramática constrastiva terá como fim primordial descrever a diversidade linguística brasileira em dialetos, transformando os estudiosos brasileiros em verdadeiros linguistas ${ }^{11}$ de campo. Não será difícil sustentar que, anos mais tarde, as anotações de Nascentes (1922) no Linguajar Carioca e as de Amaral (1920) no Dialeto Caipira serão verdadeiras gramáticas contrastivas da língua portuguesa do Brasil, subsídios para as primeiras gramáticas dialetológicas dos anos $30 \mathrm{em}$ diante.

Esta mentalidade dialetológica da agenda permanecerá nos estudos da linguagem, não como uma "tendência" ou um mainstream, mas como uma vertente, uma espécie de disciplina linguística para descrição das variedades. Uma série de trabalhos subsequentes será desenvolvida já no século XX nesta base, como os da Geografia Linguística de Silva Neto (1955) - ou mesmo Cândido Jucá (Filho) ainda nas décadas de 1930 e 1940 - até os trabalhos pelo Atlas Linguístico do Brasil na década de 1960 e seus desdobramentos em atlas regionais anos mais tarde.

Se, contudo, a espacialidade brasileira foi até aí analisada sob a perspectiva de uma agenda dialetológica, é com o advento da Sociolinguística que ela passa a ser compreendida em relação aos fenômenos de variação e mudança, relacionados de certa forma às diferenças diastráticas concernentes à língua falada no Brasil. De toda maneira, mesmo compreendendo que ocorre a partir da década de 1960 uma reestruturação na abordagem da espacialidade brasileira, e que isto tenha sido necessário para a própria constituição da Sociolinguística brasileira, num quadro geral de uma História das Ideias Linguísticas no Brasil, a temática da espacialidade nas ciências da linguagem parece permanecer. Hoje, por exemplo, fala-se em Geosociolinguística e em abordagens pluridimensionais.

\section{O espaço-tempo na Linguística brasileira}

Para estabelecer um recorte temporal sobre os estudos relativos à espacialidade brasileira, optamos inicialmente em nosso trabalho, que reconsidera uma série de outras

\footnotetext{
${ }^{11}$ Talvez seja o caso aqui de permitir à História das Ideias Linguísticas a abertura de diálogo com uma nova área de estudos em Linguística que aos poucos se consolida no Brasil, a saber a Linguística Popular. Para uma melhor definição ver Achard-Bayle; Paveau (2019). Para uma análise sob esta perspectiva e suas relações com a Análise do Discurso ver Baronas; Conti (2019).
} 
propostas para a língua portuguesa no Brasil ${ }^{12}$, por considerar as seguintes condições de produção:

a) É partir do fim do século XIX que figuram em nossa produção linguística as primeiras tecnologias brasileiras, fruto do processo de gramatização. É também dentro deste período inicial (que vai até a publicação do Dialeto Caipira e do Linguajar Carioca) que estão postas, algumas vezes pelo veículo da Filologia, as discussões a respeito da diversidade linguística no Brasil.

Figura 1: A Gramatização Brasileira.

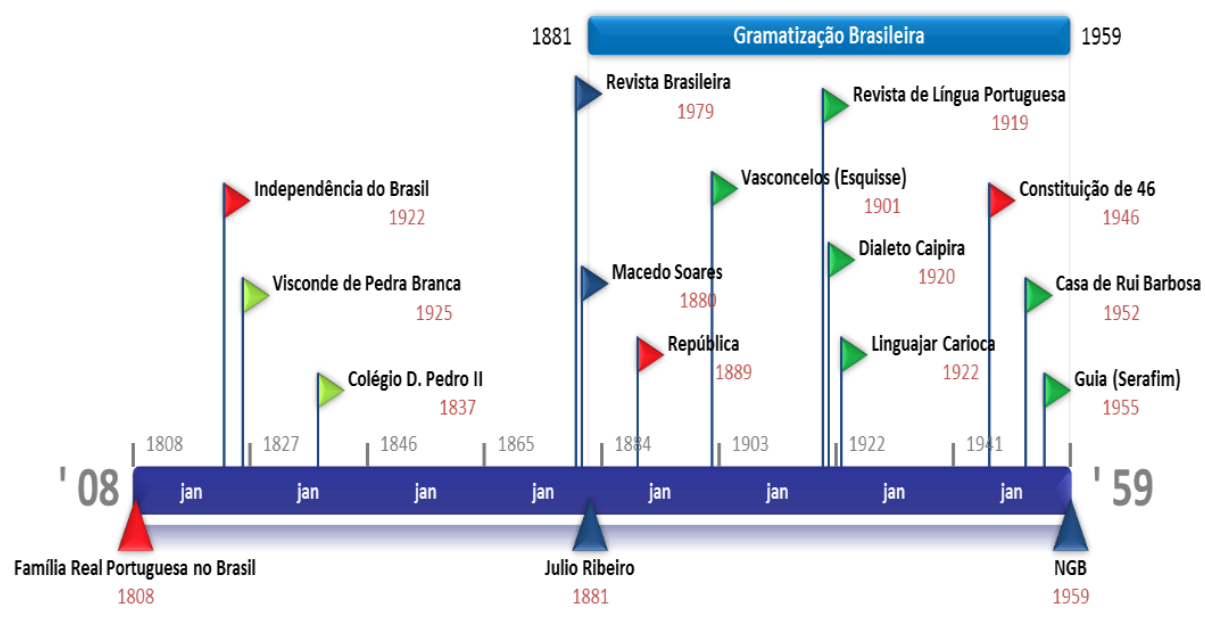

Fonte: Gonçalves (2012, p. 16).

Ressaltamos que os estudos em Filologia no Brasil, iniciados em Portugal por J. Leite Vasconcelos (1901), perduram no Brasil por décadas ainda. Basta lembrar que na década de 40 do séc. XX é criada uma comissão de estudos em Filologia, da qual alguns membros participaram do episódio da denominação do idioma nacional. Há dois atos administrativos emblemáticos para os estudos filológicos na Brasil, relativos à comissão de filologia: a constituição de 1946 e o Decreto 30.643, de 20 de março de 1952, "que, ao definir as finalidades da Comissão de Filologia da Casa de Rui Barbosa, que vinha de ser criada, assentava como a principal delas a elaboração do atlas linguístico do Brasil" (CARDOSO, 1999, p. 239).

b) Pinto (1978), por exemplo, considera que a opção pelo enfoque dialetológico em detrimento do filológico (comum mesmo nos trabalhos de natureza tópica), ocorre no período de 1920-1945. Neste período a dialetologia e a geografia linguística passam a figurar no cenário linguístico brasileiro: às vezes tão somente como um vocabulário próprio das áreas de pesquisa, às vezes como partes integrantes de algumas produções acadêmicas brasileiras ${ }^{13}$. Ocorre nesse período, também, uma tendência à orientação descritivista dos fenômenos.

\footnotetext{
${ }^{12}$ Fazemos referência aos trabalhos de Mattoso Câmara Jr. no Os estudos de português brasileiro (ver MATTOSO CÂMARA JR., 2004) e de Carlota Ferreira e Suzana Cardoso no A dialetologia no Brasil (ver FERREIRA, C.; CARDOSO, S. 1994). Ver também Brandão (1991) e Silva (2004).

13 Por exemplo, n’O Português do Brasil de Renato Mendonça de 1936 e na Gramática Histórica do Português Contemporâneo de Candido Jucá Filho de 1945. Ver Mendonça (1936) e Jucá Filho (1945) respectivamente.
} 
Figura 2: Agenda em Construção e Funcionamento.

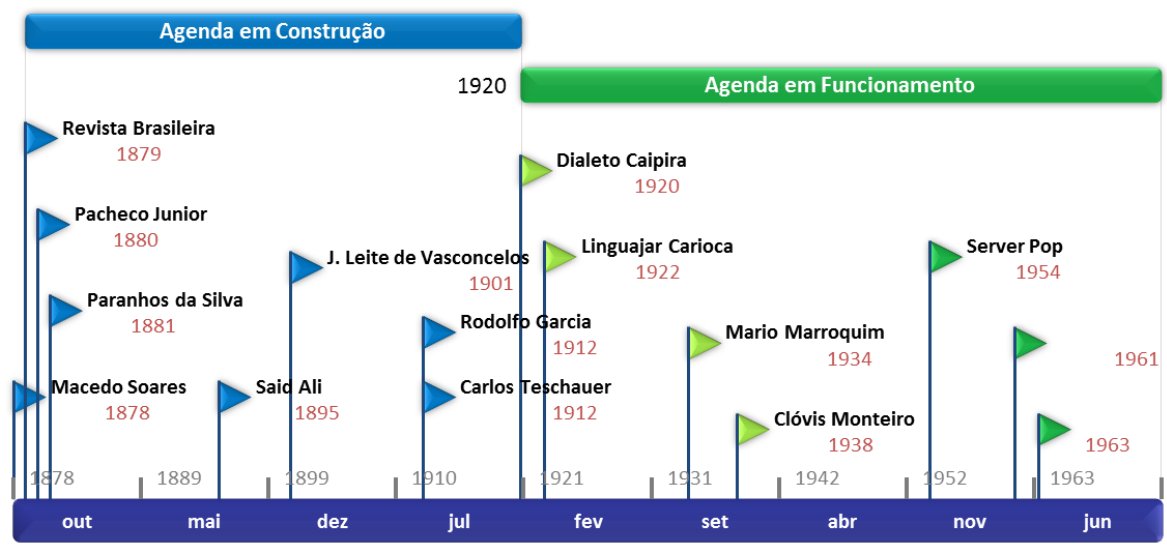

Fonte: Gonçalves (2012), p. 17.

c) A partir de 1950 a discussão sobre a diversidade linguística brasileira tomada a partir de bases dialetológicas deslocou-se de certa forma das gramáticas para a feitura dos atlas no Brasil. Os atlas linguísticos, anos mais tarde concretizados, passaram a mapear a diversidade linguística brasileira. Serão relevantes para nós as primeiras discussões e as primeiras realizações para o atlas linguístico nacional e os atlas linguísticos regionais. Neste período, vemos paralelamente a este deslocamento uma possível reorientação metodológica (uma nova instrumentação) expressa na passagem de uma dialetologia tradicional a moderna.

Figura 3: A Agenda Dialetológica.

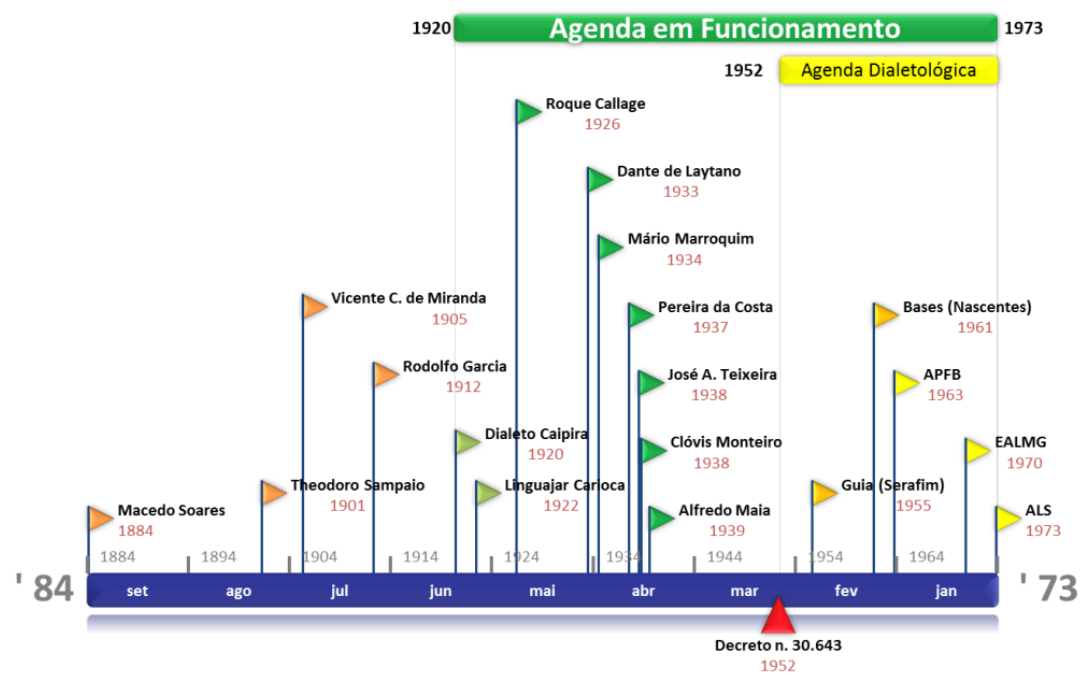

Fonte: Gonçalves (2012, p.18).

Estabelecemos, assim, dentro das fases distintas desta linha do tempo uma agenda mais ou menos regular, voltada para a descrição da diversidade da língua portuguesa falada no Brasil. Nossas considerações vão tomar, primeiramente, dois momentos distintos desta agenda da espacialidade: uma fase inicial, de construção, que vai até a publicação dos textos de Amaral (1920) e Nascentes (1922); e outra fase de funcionamento, que vai até os trabalhos para o Atlas Linguístico do Brasil. Nesta segunda fase, principalmente se pensarmos no aporte teórico e metodológico implementado, percebemos também que há 
uma diferença notável dos trabalhos sobre a espacialidade brasileira até a década de 1950 para os publicados posteriormente. Diremos que, a partir de Serafim (1955), a agenda torna-se de cunho estritamente dialetológico.

\section{A questão do tempo}

Percorremos nesta pesquisa quase cem anos da questão da espacialidade brasileira nos estudos da linguagem no Brasil. Ainda que nosso objetivo principal não tenha sido apresentar simplesmente e categoricamente uma periodização do funcionamento da agenda da espacialidade, a tarefa nos ajudou a organizar melhor nosso arquivo nesse quase um século de investigação sobre a diversidade brasileira. Foi tomando a espacialidade como um discurso, investigando suas condições de produção e sua permanência e influência no decorrer dos anos, que nos foi permitido analisar em conjunto algumas produções acadêmicas.

Sem nos desvencilhar dos acontecimentos históricos que estavam envolvidos na percepção da realidade linguística brasileira (sua diversidade e sua distribuição pelo território nacional), optamos por definir fases distintas da permanência desta agenda a partir das características que eram mais ou menos comuns aos textos e neles recorrentes. É claro que, nas bordas, nos limites destas fases, a dificuldade de separação aumentava.

Temos certa convicção de que a gramatização brasileira que se iniciou no fim do século XIX estabelece um ponto de partida produtivo, na medida em que coloca a questão da diversidade brasileira nas produções acadêmicas a partir da oposição entre a língua falada no Brasil e em Portugal. É nesse período inicial, fortemente influenciado pelos acontecimentos políticos que afetavam o Brasil, como é o caso da proclamação da República, que a discussão sobre que língua falamos? (um dialeto brasileiro ou a língua portuguesa?) vai tomar corpo através das diferenças apresentadas pelos autores ${ }^{14}$ nacionais entre a língua falada aqui e do outro lado do Atlântico.

Neste período surgem, por exemplo, as primeiras distribuições espaciais da língua falada em território nacional com os trabalhos publicados na Revista Brasileira de 1879 a 1899, nos textos do filólogo português José Leite de Vasconcelos (Ver VASCONCELOS, 1901) já na virada do século XIX para o XX e mais tarde com os trabalhos publicados na Revista de Lingua Portuguesa de Laudelino Freire de 1919 a 1924. Claro que, se interpretadas isoladamente, estas produções demonstram tomadas de posição diferentes em relação à diversidade linguística brasileira, mas se analisadas em conjunto, denotam que as interpretações desta diversidade partiam quase sempre da diferença do português no Brasil e em Portugal.

\section{A questão do espaço}

Do ponto de vista da distribuição do português do Brasil, os trabalhos de natureza tópica de Amadeu Amaral em 1920 e Antenor Nascentes em 1922 talvez sejam de fato muito distintos dos trabalhos da virada do século XIX/XX. Mas não é o caráter dialetológico das obras, apenas, que nos permite separá-las das demais, até porque se o critério para o estabelecimento desta fase for única e exclusivamente a questão do método, provavelmente falaríamos de um conjunto muito maior de textos. $\mathrm{Na}$ primeira fase, a oposição dialeto brasileiro x língua portuguesa produz efeitos que levam ao afastamento

14 Talvez seja o caso de pensar aqui, à la Maingueneau (2010), em "auctor" (pg.30) e na sua "imagem de..." (Pg. 142): “[...] para que um indivíduo seja plenamente "auctor”, é necessário que terceiros o instituam como tal, mediante a produção de enunciados sobre ele e sobre sua obra, em suma, conferindo-lhe uma "imagem de autor"” (as aspas são do próprio Maingueneau). 
das duas línguas nos diferentes continentes e, ao mesmo tempo, direcionam os estudos da linguagem no Brasil para o estabelecimento de uma norma padrão (uma língua nacional).

As práticas decorrentes desta tomada de posição em relação à língua nacional têm características distintas, e talvez até mesmo produzam instrumentos linguísticos diferentes como as gramáticas escolares de um lado e as monografias dos falares regionais de outro. As práticas são de fato distintas, pois são afetadas por diferentes condições de produção.

Talvez um estudo meticuloso (mais minucioso) das gramáticas brasileiras (e um grande número de produções acadêmicas entrariam nesse pacote mesmo sem o nome específico de gramática), permitisse, em face das questões que envolvem o ensino da língua portuguesa, separá-las inicialmente em dois grandes grupos. De um lado as escolares, presas ao ensino e manutenção do vernáculo culto escrito e, de outro, as gerais (científicas), nas quais a presença do estudo dos falares regionais se revelasse mais intensamente.

Pensemos, por exemplo, na introdução de um jargão específico, científico, de um campo específico da Linguística em algumas produções acadêmicas da década de 1930 e 1940. Além da gramática de Jucá (1945), poderíamos ainda ter tomado o exemplo de Nascentes no Léxico ${ }^{15}$ e 1946, quando introduz o jargão da dialetologia e da geografia linguística. Achamos suficiente apontar aqui que o discurso da espacialidade permanece sendo reafirmado mesmo dentro de uma certa estabilidade dos instrumentos linguísticos, mesmo depois de algumas décadas.

Em outra frente, tentamos relacionar, na medida do possível, as mudanças que ocorrem na década de 1950 e 1960 no aparato teórico-metodológico para a descrição da diversidade brasileira, com o deslocamento do lugar de produção deste saber linguístico. Não podemos assim pensar este saber linguístico como o mesmo, principalmente se conseguimos inscrevê-lo na própria constituição da Linguística moderna no Brasil.

As condições que permitem produzir um discurso sobre a espacialidade brasileira a partir da década de 1950 são outras e estão claramente determinadas pela produção deste saber no ensino superior. Num certo sentido, os investimentos de Serafim (1955) no campo da dialetologia e geografia linguística de fato remetem este saber à investigação científica da espacialidade, a um aprimoramento técnico, que lhe permite fazer um recorte nas produções acadêmicas da área, produzindo um passado para a disciplina no Brasil, um momento anterior que deveria ser superado e renovado.

Mas esse efeito para nós cria uma lacuna na história da mentalidade dialetológica. Se pensássemos a partir dos atlas regionais, e não do nacional, identificaríamos que haveria apenas um número muito reduzido de atlas regionais publicados, pelo menos até a década de $1970^{16}$. Nas palavras de Cardoso (1999):

Retomando a ideia de um atlas linguístico do Brasil, lançada em 1952, pesquisadores da área de Dialectologia reúnem-se em Salvador, Bahia, em novembro de 1996, no Seminário Caminhos e Perspectivas para a Geolingüística no Brasil e assumem esse desafio. Nesses três dias de discussão em que foram abordadas temáticas referentes a uma política geolingüística para o Brasil e a questões metodológicas em geral, ficou também acertada a criação de um Comitê Nacional que, a partir daquele momento, se encarregaria de dar curso às decisões do encontro e implementar o projeto nacional para execução do atlas linguístico do Brasil[...] (CARDOSO, 1999, p. 248).

${ }^{15}$ Léxico de Nomenclatura Gramatical Brasileira. Ver Nascentes (1946).

16 Ver Brandão (1991) sobre os atlas regionais publicados no Brasil neste período.

Revista do GELNE, Natal/RN, Vol. 23 - Número 1: p. 56-71. Janeiro. 2021 
Esta lacuna talvez seja propiciada pela interferência e assunção de um outro paradigma linguístico de investigação a partir da década de 1960. De maneira muito superficial, podemos dizer que a constituição da ciência linguística moderna no Brasil tem mais ou menos definida sua inauguração com a linguística estruturalista de Mattoso Câmara Jr. na década de 1950. Segundo Guimarães (2004, p.33):

No Rio de Janeiro, se há uma permanência dos estudos históricos no Curso de Letras da Universidade do Brasil [...], há também a configuração do início da linguística moderna no Brasil (especificamente o estruturalismo) através da obra de Mattoso Câmara (GUIMARÃES, 2004, p.33).

A linguística moderna no Brasil é depois afetada pela introdução dos estudos gerativistas. Mais tarde, vão fazer parte também destas novas abordagens os estudos em Sociolinguística no Brasil, que vão interferir profundamente na análise e descrição da diversidade brasileira, e, claro, nos trabalhos da dialetologia e da geografia linguística no país.

\section{CONCLUSÃO}

Apresentamos neste texto o processo de gramatização e seus efeitos no espaçotempo brasileiro do final do século XIX a meados do século XX. Ao analisarmos o que seria a gramatização brasileira, percebemos, de um lado, a particularidade de que no Brasil o processo se deu na base de uma mesma língua e, de outro, que os próprios instrumentos linguísticos (ou tecnologias) podem ser estendidos para além de gramáticas e dicionários. Verificamos que se constituiu uma agenda de estudos no Brasil neste período presa à análise da diversidade linguística nacional. Discutimos, a partir daí, uma proposta de periodização dos estudos linguísticos no Brasil, com vistas ao estudo da espacialidade na Linguística nacional.

A periodização nos permitiu pensar também nos próprios limites e alcances do nosso conceito de agenda linguística da espacialidade. O primeiro problema residiu, assim, nos efeitos que a gramatização brasileira acarretou à permanência desta agenda nos estudos da linguagem no Brasil. Temos convicção de que podemos relacionar com certa segurança o surgimento deste discurso sobre a espacialidade aos próprios efeitos da gramatização no Brasil. De fato, não vemos com muita distância as relações possíveis causadas pela disjunção da língua portuguesa promovida pela gramatização, e seus efeitos diretos nos estudos da linguagem, como a descrição das formas distintas na fonética, na sintaxe e no léxico das duas línguas no final do século XIX até a consolidação de uma língua oficial no Brasil, distinta, portanto, da de Portugal.

A gramatização cessa, ou melhor dizendo, tem diminuídos seus efeitos nos anos de 1940 com os acontecimentos que vão promover e legitimar a língua nacional como língua oficial dentro de uma política de línguas. Como as questões sobre a espacialidade e a diversidade linguística permaneceram, achamos por certo caracterizar, portanto, esta desvinculação da agenda linguística do processo da gramatização no Brasil como uma das marcas deste novo período que vai abarcar as produções acadêmicas principalmente na década de 1950. Em função da gramatização, a agenda deveria ser assim reestruturada.

Como não queríamos tornar tão complexa nossa periodização, marcamos esta diferença na agenda linguística da espacialidade brasileira com o estabelecimento de períodos distintos de construção e de funcionamento. É dentro deste período de funcionamento que a agenda vai se tornar, para nós, dialetológica. Estabelecemos assim, dois períodos, em três diferentes fases: na construção, o estabelecimento da pauta desta agenda linguística desde a segunda metade do século XIX; e no funcionamento, as práticas 
que estiveram envolvidas na descrição da diversidade brasileira até os anos 60 do século XX.

\section{Referências Bibliográficas}

ACHARD-BAYLE, Guy; PAVEAU, Marie-Anne. Linguística Popular - a linguística 'fora do templo': Definição, Geografia e Dimensões. Fórum Linguístico. Vol. 16, No 04, 2019, p. 4257-4270.

AGUILERA, Vanderci. Atlas Linguístico do Paraná (ALPr). Curitiba, PR: Imprensa Oficial do Estado, 1994.

1998.

(org.) A Geolinguística no Brasil. Londrina, PR: Editora UEL,

AMARAL, Amadeu. O Dialeto Caipira. São Paulo, SP: Casa editora “O Livro”, 1920.

AUROUX, Sylvain. A Revolução Tecnológica da Gramatização. Campinas, SP: Editora da Unicamp. 2009.

BALDINI, Lauro. A Nomenclatura Gramatical Brasileira Interpretada. 1999. Dissertação (Mestre). Campinas, SP: Instituto de Estudos da Linguagem (IEL)/Unicamp, 1999.

BARONAS, Roberto; CONTI, Tamires. Notas sobre a Possibilidade de um Trabalho no Carrefour Epistemológico entre a Linguística Popular e os Estudos do Discurso. Fórum Linguistico. Vol. 16, No 04, 2019, p. 4285-4294.

BRANDÃO, Silvia. A Geografia Lingüística no Brasil. São Paulo, SP: Ática, 1991.

CARDOSO, Suzane. A dialectologia no Brasil: perspectivas. D.E.L.T.A., Vol. 15, N. ${ }^{\circ}$ ESPECIAL, 1999, p. 233-255.

CASTANHEIRA, Carla. Práticas Linguísticas e Espacialidades: Um Retorno ao "Lugar". Revista Porto das Letras. Vol. 04, Nº1, 2018, p. 83-99.

FERREIRA, Carlota; CARDOSO, Suzane. A Dialetologia no Brasil. São Paulo, SP: Contexto, 1994.

FOUCAULT, Michel. A arqueologia do Saber. $7^{\text {a }}$ ed. Rio de Janeiro, RJ: Forense Universitária, 2004.

Arqueologia das Ciências e História dos Sistemas de Pensamento; organização e seleção de textos: Manoel Barros da Motta; tradução: Elisa Monteiro. Série Ditos \& Escritos. Rio de Janeiro, RJ: Forense Universitária, 2005.

FREIRE, Laudelino. Revista da Língua Portuguesa - Archivo de estudos relativos ao idioma e literatura nacionais. Rio de Janeiro, RJ: Rohe, 1919-1924.

GONÇALVES, Marcelo. Teorias linguísticas da espacialidade: uma agenda dialetológica na gramatização do português do Brasil. Tese de Doutorado. Programa de 
Pós-Graduação em Linguística, Instituto de Estudos da Linguagem (IEL), UNICAMP, Campinas, SP, 2012.

GUIMARÃES, Eduardo. História da Semântica. Campinas, SP: Pontes, 2004.

JUCÁ FILHO, Cândido. Gramática Histórica do Português Contemporâneo. Rio de Janeiro, RJ: Epasa, 1945.

MACIEL, Maximino. Grammatica Descriptiva Baseada nas Doutrinas Modernas. 11 edição. Rio de Janeiro, RJ: F. Alves, 1928.

MAINGUEnEAU, Dominique. Doze Conceitos em Análise d Discurso; Organização Sírio Possenti, Maria Cecília Perez de Souza-e-Silva; Tradução Adail Sobral... [et al] - São Paulo: Parábola Editorial, 2010.

MATTOSO CÂMARA JR, Joaquim. História da Lingüística. Rio de Janeiro, RJ: Vozes, 1975.

MAZIÈRE, Francine. A Análise do Discurso: História e Práticas; Tradução Marcos Marciolino - São Paulo: Parábola editorial, 2007.

MIGNOLO, Walter. Histórias Locais, Projetos Globais: colonialidade, saberes subalternos e pensamento liminar. Trad. Solange Ribeiro de Oliveira. Belo Horizonte: UFMG, 2003.

NASCENTES, Antenor. O Linguajar Carioca em 1922. Rio de Janeiro, RJ: Süssekind de Mendonça \& Comp., 1922.

Janeiro, RJ: CBAG, 1946.

Léxico de Nomenclatura Gramatical Brasileira. Rio de

ORLANDI, Eni. (org.) História das Idéias Lingüísticas: construção do saber metalingǘstico e constituição da língua nacional. Campinas, SP: Pontes; Cáceres, MT: Unemat Editora, 2001.

Pontes Editores, 2007a.

Análise de Discurso: Princípios e Procedimentos. Campinas, SP: (org.) Política Lingüística no Brasil. Campinas, SP: Pontes Editores, 2007b.

PÊCHEUX, Michel; FUCHS, Catherine. A propósito da Análise Automática do Discurso. In : GADET, Françoise; HAK, Tony (org). Por uma análise automática do discurso. Campinas: Ed. Unicamp, 1990, p.163-252.

PENNYCOOK, Alistair. Language as local practice. New York: Routledge. 2010.

PINTO, Edith. O Português do Brasil - Vol. 1 e 2. São Paulo, SP: Edusp, 1978.

SAID, Edward. Orientalismo. São Paulo, SP: Cia das Letras, 2007.

Cultura e Imperialismo. São Paulo, SP: Cia das Letras, 2011.

SILVA, Rosa. Ensaios para uma socio-história do Português Brasileiro. São Paulo, SP: Parábola, 2004. 
SILVA NETO, Serafim. Guia para Estudos Dialetológicos. Florianópolis, SC: Faculdade Catarinense de Filosofia, 1955.

TOULMIN, Stephen. Cosmopolis: the hidden agenda of modernity. Chicago: Univ. of Chicago, 1992.

VASCONCELOS, José Leite. Esquisse D'une Dialectologie Portugaise. Thèse pour le doctorat de L’université de Paris (Faculté des Lettres). Paris, França: 1901.

Submetido em 26/08/2020

Aceito em 17/11/2020 